\title{
Effect of coal mine organic aerosol on the methane/air lower explosive limit
}

\author{
S. V. Valiulin ${ }^{1,2,3}$ - A. A. Onischuk ${ }^{1,2,3}$ - A. M. Baklanov ${ }^{1,2}$ - A. A. Bazhina ${ }^{1,3}$ • \\ D. Yu. Paleev ${ }^{4}$ V. V. Zamashchikov ${ }^{1,2} \cdot$ A. A. Korzhavin ${ }^{1}$ - S. N. Dubtsov ${ }^{1}$
}

Received: 7 November 2019/Revised: 29 January 2020/Accepted: 17 March 2020/Published online: 28 March 2020

(C) The Author(s) 2020

\begin{abstract}
Organic aerosol is formed in coal mines due to heat release and evaporation of organics from coal during the longwall operation. This frictional heating occurs when a metallic cutting bit strikes a rock. Thus formed organic aerosol can contribute significantly to the explosivity of methane/air atmosphere in coal mines. In this paper, the flammable limits for the methane-air mixtures with organic aerosol are determined. For this purpose, organic aerosol is synthesizes from the coal-tar pitch in a laboratory evaporation-nucleation flow chamber. Aerosol particles synthesized under laboratory conditions are aggregates consisting of small primary particles with the fractal-like dimension $D_{\mathrm{f}}=2.0 \pm 0.1$, which is close to $D_{\mathrm{f}}$ $=2.1 \pm 0.1$ of coal mine aerosol. It is shown that the flammability of organic aerosol/methane mixture in air is in good agreement with the Le Chatelier additive principle. The lower ignition limit for the pure organic aerosol in air is $44 \mathrm{~g} / \mathrm{m}^{3}$.
\end{abstract}

Keywords Organic aerosol $\cdot$ Explosivity of aerosol $\cdot$ Coal mine $\cdot$ Methane-air mixtures $\cdot$ Agglomeration

\section{Introduction}

Explosions in coal mine atmosphere are the most feared hazard. Although many safety measures have been investigated and developed in coal mining industry, many disasters occur every year in this industrial activity all over the world. In the twentieth century, about 10,000 workers had died in the underground coal mining disasters in the United States (Cheng 2018). The twentfirst century did not bring any improvements in the safety in coal mines. The major explosions with numerous victims occurred during the last decade in Pike River Mine, New Zealand (2010) -29 deaths, Upper Big Branch Mine, US (2010)—29, Sorange, Pakistan (2011)—45, Babao Mine,

S. V. Valiulin

valiulin@kinetics.nsc.ru

1 Voevodsky Institute of Chemical Kinetics and Combustion, Novosibirsk 630090, Russia

2 Novosibirsk State University, Novosibirsk 630090, Russia

3 Novosibirsk State Pedagogical University, Novosibirsk 630126, Russia

4 Institute of Coal, Kemerovo 650610, Russia
China (2013)_-36; Machang Coal Mine, China (2013)_-25; Taozigou Coal Mine, China (2013)_-28; Soma Coal Mine, Turkey (2014) — 301; Zasyadko Coal Mine, Ukraine (2015)_34; Severnaja -Vorkutaugol, Russia (2016)_-36, ZemestanYurt Coal Mine, Iran (2017)_-35, CSM hard coal mine, Czech Republic (2018)_13, Skhidkarbon coal mine, Ukraine (2019) - 17. It seems to be evident that the coal mine industry is in need of further research for explosion prevention.

Commonly, coal mine explosions start with the ignition of the underground combustible gases. Methane is the most dangerous gas in underground coal mining. It is explosive within the range 5-15 molar\% in mixture with air. Besides, other combustible components can add to the explosion potential of coal mine atmosphere, for instance, higher hydrocarbons (Cashdollar 2008; Wang et al. 2014), carbon monoxide, hydrogen sulfide etc. (Cheng 2018), which are by-products of the coal formation process. Most often, gas explosion causes an explosion of coal dust, resulting in violent devastation. During the recent years, many researchers studied coal dust explosions (Sapko et al. 2007; Eckhoff 2012; Ajrash et al. 2016, 2017; Tan et al. 2020). However, there is still acute need for further research into the mechanism of coal dust associated with gas explosions. 
Coal mine explosions start mostly from ignition near the face (Pomroy and Carlgiet 1995). Methane released at the longwall face contributes only $10 \%-20 \%$ of the total amount of methane emitted from the entire longwall panel (Kissell and Cecala 2006). However, methane released along the face can cause ignition. At present, a hot strike on the rock left due to frictional abrasion behind the cutting tool is considered as the primary igniting source of heat (Trueman 1985; Phillips 1996; Pomroy and Carlgiet 1995). This hot streak can ignite the nearby combustible atmosphere and lead to a fireball. Although the resulting fireballs are often small and shortlived, there is a possibility of coal dust lifting by the pressure front of a primary explosion and the formation of the dust/air mixture, creating an explosive zone in front of the flame and providing the propagation of a more violent secondary explosion throughout the mine (Krog and Schatzel 2009; Cheng et al. 1987; Pejic et al. 2017). To prevent explosions, it is important to know the mechanism of frictional ignition, and its precursors are to be characterized. A statistical analysis of all possible controlling factors in frictional ignitions was made by Krog and Schatzel (2009). It is found that there is no relationship between methane emissions and the number of frictional ignitions in coal mines. Therefore, the contribution of other combustible components to the ignition mechanism is to be studied.

It was determined by Baklanov et al. (2015), Valiulin et al. (2016) and Onischuk et al. (2017) that the release of frictional heat results in the emission of organic components $\left(\mathrm{C}_{14}-\mathrm{C}_{22}\right)$ along with methane. The evaporated organic matter is transformed into aerosol aggregates, and the mass concentration of organic aerosol is comparable to that of emitted methane. Therefore, the resulting aerosol-methane mixture can be explosive even with methane concentrations less than the lower explosive limit in methane-air mixture. Hence, the formation of organic aerosol should be considered when estimating the safety limits in coal mines. Unfortunately, until now there are no experimental data on the explosive limits for this kind of aerosol/methane mixtures in air.

The objective of this paper is to measure the flammable limits for the methane-air mixtures with aerosol formed from the organic components of coal. For this purpose, the organic aerosol is generated in laboratory, and the aerosol generation conditions are chosen to provide the aerosol morphology close to that in coal mines.

\section{Materials and methods}

\subsection{Aerosol sampling in the coal mine}

As the aerosol morphology can have a substantial effect on the explosivity of the aerosol-methane-air mixtures, the shape of aerosol particles formed in a coal mine is to be characterized. The aerosol particles formed in the "November 7th" coal mine (Kuznetsk coal basin, Russia) during the operation of a longwall shearer are sampled and then studied using a JEM 100SX transmission electron microscope (TEM). Sampling for the TEM analysis is carried out thermophoretically. For this purpose, a specially elaborated sampler is used. It consists of a quartz cylindrical flow chamber with the inner diameter $1.0 \mathrm{~cm}$ and length $20 \mathrm{~cm}$, air dryer at the chamber inlet and a sucking micropump at the outlet. A grid for electron microscopy, covered with polyvinyl formal film, is fixed inside the flow chamber to the inner wall. The chamber wall is cooled from outside with liquid nitrogen to create the radial temperature gradient of $100 \mathrm{~K} / \mathrm{cm}$ inside the chamber. The inlet air dryer is formed by two concentric cylinders, an inner wire screen and an outer metal tube. Desiccant silica gel beads are fixed between the wire screen and the outer tube. As the aerosol particles move through the inner cylinder, water vapor diffuses into silica gel through the screen to be adsorbed. Then the aerosol particles pass through the flow chamber with the flow rate of $7 \mathrm{~cm}^{3} / \mathrm{s}$ and are deposited onto the TEM grid due to the radial temperature gradient. As the air is blown along the longwall face, the TEM sampling is made $30 \mathrm{~m}$ downstream of the operating shearer.

\subsection{Laboratory aerosol generation and sampling}

It was determined by Valiulin et al. (2016) and Onischuk et al. (2017) that the reason for the formation of organic aerosol in coal mines is in frictional heating, which occurs when a metal cutting bit strikes the rock. The heat release is so strong that it causes hydrocarbon boiling in the carbon matrix. Due to boiling, the organic vapor discharges into the ambient atmosphere with a high rate, which results in the formation of aerosol aggregates consisting of small primary particles. To simulate the organic aerosol of coal mines, we used the evaporation-nucleation method (Onischuk et al. 2012, 2014). The maternal substance for the aerosol generation was the coal-tar pitch prepared from coal taken from the Kuzbass "November 7th" mine. To extract the coal-tar pitch, we heated coal for $5 \mathrm{~h}$ at a temperature of $620 \mathrm{~K}$ in the vertical cylindrical flow-type reactor in Ar flow from top to bottom, and collected the segregated liquid hydrocarbons downwards. Then volatile hydrocarbons were removed from the collected coal-tar pitch by blowing a flow of Ar through it for $8 \mathrm{~h}$ at $373 \mathrm{~K}$ in a bubbling flask. Then silica gel beads were saturated with the coal-tar pitch and placed into the evaporation-nucleation aerosol generator. The aerosol generator consists of two consecutive cylindrical parts: saturation chamber and nucleation chamber (Fig. 1). Their inner diameter is $2.0 \mathrm{~cm}$. A flow of nitrogen is supplied to the inlet of 


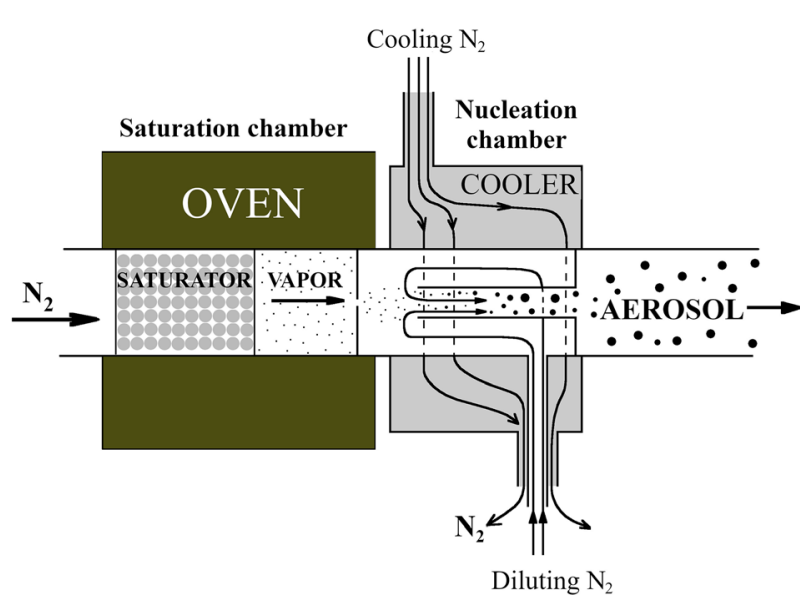

Fig. 1 Schematic of aerosol generator

saturation chamber, which contains silica gel beads with the coal-tar pitch. The temperature of the saturation chamber is $700 \mathrm{~K}$. The nitrogen flow passing through the beads gets saturated with hydrocarbons, and then the saturated vapor enters the nucleation chamber, where it is mixed with the cold flow of nitrogen. Thus homogeneous nucleation starts. The diluting $\mathrm{N}_{2}$ is cooled down by blowing a flow of cold nitrogen with the flow rate of $10 \mathrm{~L} /$ min through a cooling jacket $7 \mathrm{~cm}$ long. The flow of cold nitrogen is obtained by extruding gas from a Dewar vessel with liquid nitrogen using an internal heater. The temperature $T_{\mathrm{d}}$ of diluting gas is a crucial parameter, which determines supersaturation ratio in the zone of homogeneous nucleation. For $T_{\mathrm{d}}$ equal to the room temperature, the final aerosol consists of single spherical particles. At lower temperatures, it is formed as aggregates consisting of small primary particles. Thus, the temperature $T_{\mathrm{d}}$ is a parameter which determines the particle shape. In our experiments, the temperature of diluting gas was set at $T_{\mathrm{d}}=170 \mathrm{~K}$ to obtain the morphology of resulting aerosol particles close to that of the particles sampled in the coal mine. Aerosol sampling for TEM in the laboratory is carried out using the same equipment as in the coal mine.

\subsection{Measurements of explosivity of aerosol- methane-air mixtures}

The explosivity of aerosol-methane-air mixtures is studied in a spherical bomb $10 \mathrm{~L}$ in volume, constructed at the Institute of Chemical Kinetics and Combustion (Novosibirsk). For this purpose, a mixture of synthetic air with organic aerosol is prepared as shown in Fig. 2. To generate the organic aerosol, nitrogen is supplied to the inlet of saturation chamber with the flow rate $F_{1}=0.50 \mathrm{~L} / \mathrm{min}$ (at room temperature and atmospheric pressure), and diluting nitrogen is supplied to the nucleation chamber with the flow rate $F_{2}=1.00 \mathrm{~L} / \mathrm{min}$. Then oxygen and methane are admixed to the aerosol stream with the flow rates $F_{3}$ and $F_{4}$, respectively. The oxygen flow rate is fixed $\left(F_{3}=0.40 \mathrm{~L} / \mathrm{min}\right)$ to be in accord with the fraction of oxygen in the air. The methane flow rate $F_{4}$ is varied in the range $0.0-0.12 \mathrm{~L} / \mathrm{min}$, which corresponds to the molar fraction of methane in the resulting mixture of $0.0-0.06$. The aerosol mass concentration is varied within the range $0-50 \mathrm{~g} / \mathrm{m}^{3}$ by changing the mass of maternal substance charged to the saturator. Two ports equipped with valves (inlet $\mathrm{V}_{2}$ and outlet $\mathrm{V}_{3}$ ) are used to fill the bomb with the combustible mixture. At first, the bomb is pumped out to a pressure of $10^{-1}$ Torr, and then it is filled with a mixture of synthetic air + methane through the aerosol generator (while the oven is switched off) to the atmospheric pressure through the inlet port with the outlet valve closed. Afterwards, the oven of aerosol generator is heated, and the aerosol-methane mixture in synthetic air is blown through the bomb. The combustible mixture passes through the bomb during some time with the inlet and outlet valves open, and then the flow is stopped by closing these valves. To avoid aerosol stratification, a small fan is running inside the bomb while the reaction mixture is passing through it. The aerosol mass concentration in the bomb is measured by sampling aerosol to filter 2 (just before closing the valves $\mathrm{V}_{2}$ and $\mathrm{V}_{3}$ ) and weighting. The mixture is ignited with a $\mathrm{Ni} / \mathrm{Cr}$ heater located in the center of the bomb. The heater is made of a double filament spiral $15 \mathrm{~mm}$ long, $2 \mathrm{~mm}$ in diameter. The filament diameter is $0.1 \mathrm{~mm}$. The capacitor discharge is used for heating. The discharge time and energy are $1.8 \times 10^{-3} \mathrm{~s}$ and $8 \mathrm{~J}$, respectively. The pressure rise is recorded with an inductive pressure transducer.

\section{Results and discussion}

A TEM image of aerosol particles sampled in the coal mine is shown in Fig. 3. Aerosol is formed as aggregates consisting of small primary particles. The aggregate shape can be characterized in terms of the so-called fractal-like dimension $D_{\mathrm{f}}$ which links the aggregate mass $M$ and radius $R$ via the following power relationship (Friedlander 2000; Samson et al. 1987; Rogak et al. 1991):

$M=k R^{D_{\mathrm{f}}}$

where $k$ is a constant. The geometric radius $R$ of each aggregate in TEM images is determined as

$R=\frac{1}{2} \sqrt{L W}$

where $L$ and $W$ are the length and width of the smallest rectangle enclosing a single aggregate image. The aggregate mass $M$ in relative units is determined through densitometric processing of TEM images of the aggregates. It 


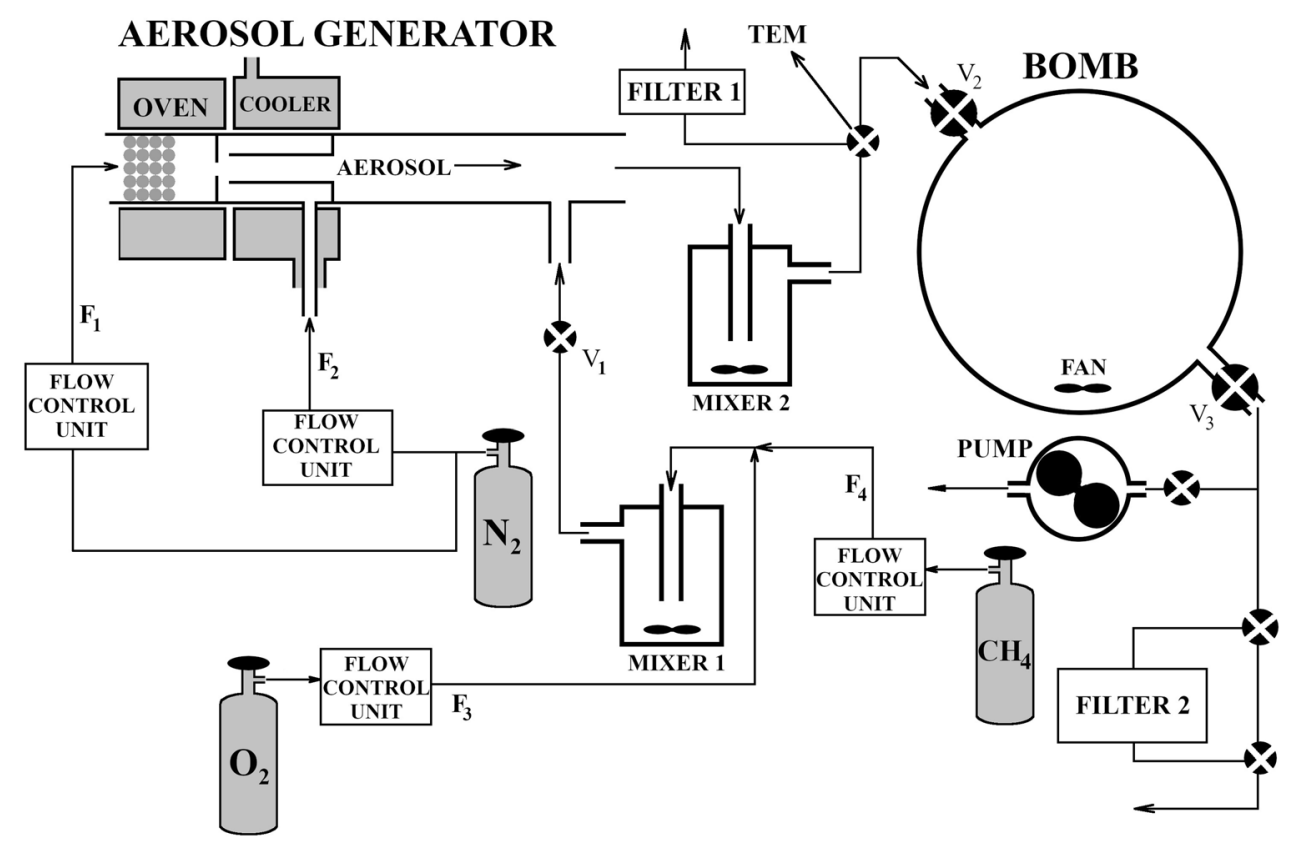

Fig. 2 Schematic of ignition experiments

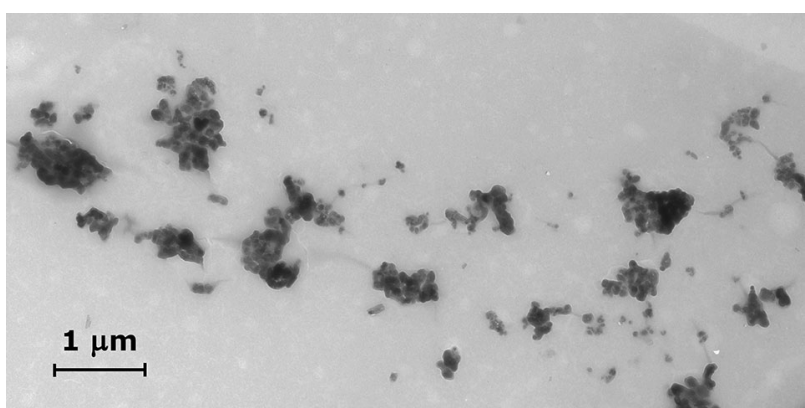

Fig. 3 TEM image of aerosol aggregates sampled in coal mine

is assumed that the local optical density is approximately proportional to its thickness. Therefore, the total aggregate mass is considered to be proportional to the integral optical density (Samson et al. 1987; Rogak et al. 1991). Another way to estimate the mass of aggregates is to subdivide the aggregate image into subunits and approximate each subunit by a sphere. Then, the aggregate volume is estimated as a sum of the volumes of spheres, which is proportional to the aggregate mass. An example of the aggregate approximation by circles is shown in Fig. 4. Figure 5a shows aggregate mass $M$ versus radius $R$ in logarithmic coordinates for the aerosol aggregates sampled in coal mine, as determined from the integral optical density. The fractal-like dimension is found to be $D_{\mathrm{f}}=2.1 \pm 0.1$. The approximation of aggregates by circles gives the value $D_{\mathrm{f}}=2.2 \pm 0.1$ (Fig. 5b). Thus, the two methods of TEM image processing give the same value of fractal-like dimension within the experimental accuracy. The value $D_{\mathrm{f}}$ depends on the aggregation mechanism. For diffusion- limited aggregation, it is within the range 1.7-1.9. If restructuring occurs during aggregation or vapor condensation, the value $D_{\mathrm{f}}$ is in the range 2-3 (Friedlander 2000; Samson et al. 1987; Rogak et al. 1991; Katzer et al. 2001; Jang and Friedlander 1998). In our case, aggregation is probably controlled by the Brownian diffusion accompanied by vapor condensation. The size distribution for the coal mine aggregates is given in Fig. $6 \mathrm{a}$.

To imitate the organic aerosol of coal mines, the laboratory aerosol generator is used as shown in Fig. 1. The maternal substance consisting mainly of $\mathrm{C}_{14}-\mathrm{C}_{22}$ hydrocarbons (Valiulin et al. 2016) is charged to the saturator. The mass of the charged substance is varied within the range $0-10 \mathrm{~g}$. The heating temperature in the saturation chamber is $700 \mathrm{~K}$, which exceeds the boiling temperature of the major components of the maternal mixture. Intensive boiling of hydrocarbons in the saturation chamber results in high vapor concentration. When mixed with the diluting flow in the nucleation chamber, the vapor becomes supersaturated due to temperature decrease, and homogeneous nucleation starts. The rate of homogeneous nucleation increases with supersaturation (the ratio of vapor pressure to the saturated vapor pressure), and the shape of aerosol particles is determined by a competition between nucleation and vapor-to-particle deposition. At relatively high temperature of the diluting gas, supersaturation is low and therefore the nucleation rate is also low. In this case, the vapor is mainly consumed not for nucleation but for the condensation on the surface of particles. The low nucleation rate results in the low particle number concentration. Therefore, the rate of second-order particle-particle 


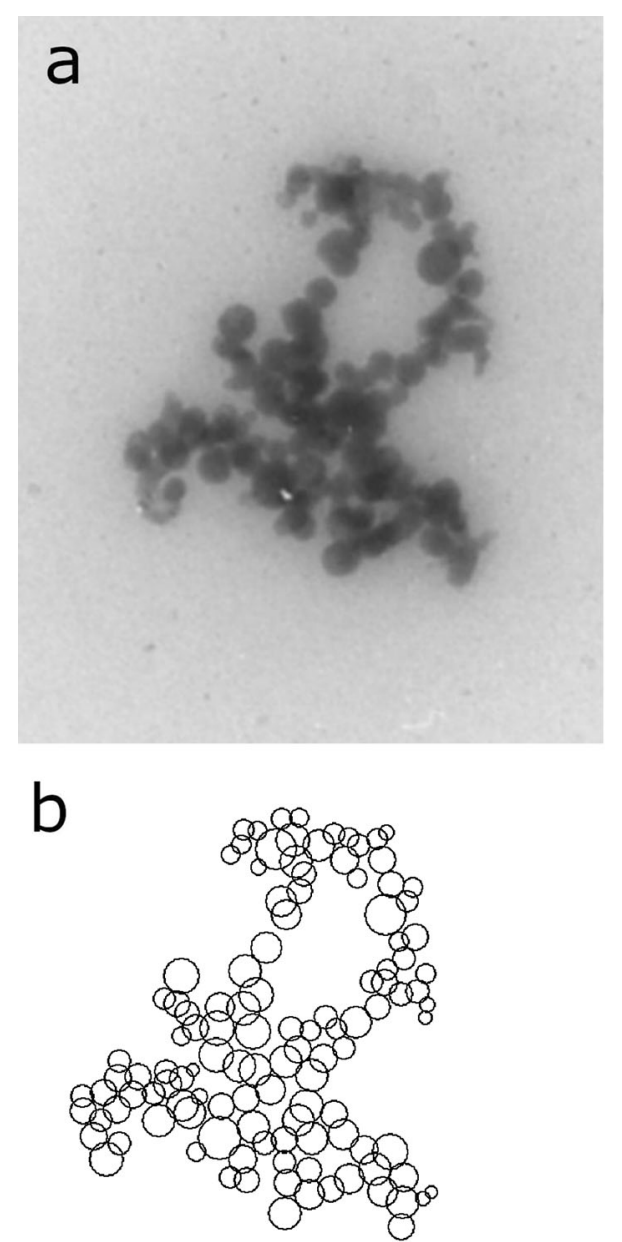

Fig. 4 Example of TEM image of aerosol aggregate sampled in the coal mine (a), and its approximation by spheres (b)

coagulation process is negligible, and single particles are formed. At a low temperature of diluting gas, the nucleation rate is high, and therefore the vapor is quickly consumed in the nucleation process. Because of high nucleation rate, the particle concentration is high. As the aggregation of particles follows the second-order kinetics, at high particle concentration it makes a significant contribution to the aerosol formation process resulting in fractal-like aggregates.

Figure 7 shows a TEM image of particles formed in the laboratory aerosol generator for the temperature of diluting gas equal to the room temperature $\left(20^{\circ} \mathrm{C}\right)$. One can see that single particles are formed, in contrast to fractal-like aggregates observed in the coal mine. To generate the particles with the shape close to that in the coal mine, we decreased the temperature of diluting gas to $170 \mathrm{~K}$ using the blow of $\mathrm{N}_{2}$ from the Dewar vessel with liquid nitrogen for cooling. In this case, the resulting particles are aggregates as can be seen in Fig. 8. Figure 9 shows aggregate mass $M$ versus radius $R$ in logarithmic coordinates for the

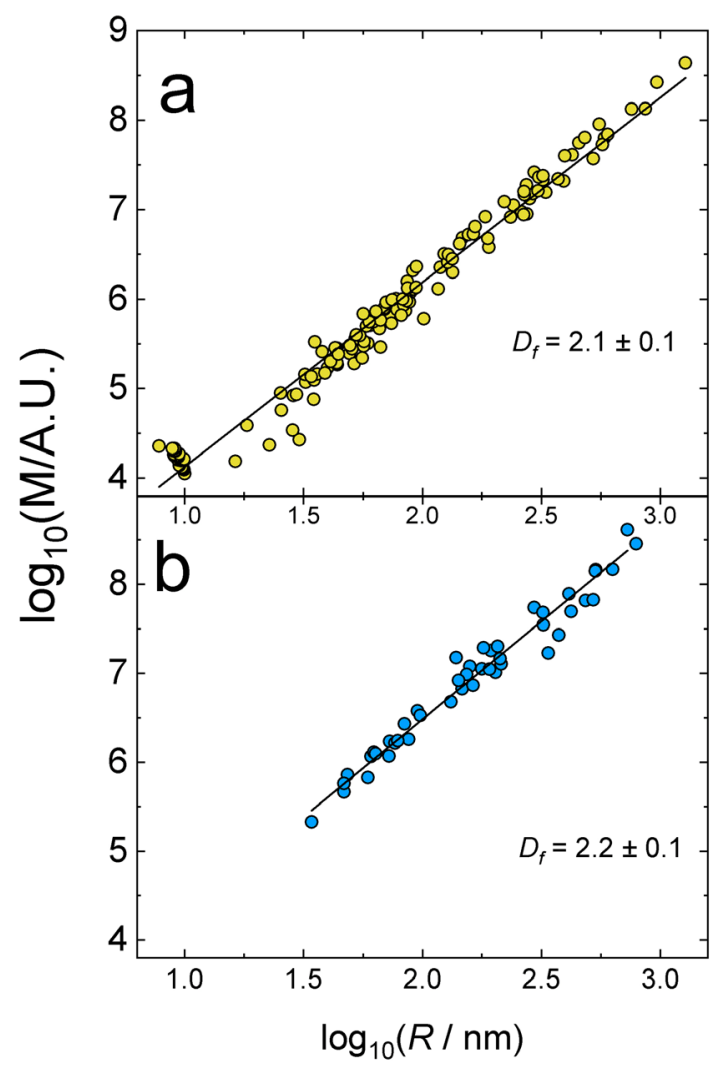

Fig. 5 Aggregate mass versus radius for aerosol particles sampled in the coal mine; a densitometric elaboration of TEM images, $\mathbf{b}$ aggregate approximation by spheres. Solid lines follow Eq. (1)

laboratory aerosol aggregates as determined from the integral optical density. The fractal-like dimension is $D_{\mathrm{f}-}$ $=2.0 \pm 0.1$, which is in reasonable agreement with the fractal dimension for the coal mine aerosol (see Fig. 5a). The size distribution of the laboratory aggregates (Fig. 6b) is in good agreement with that for the coal mine aggregates (Fig. 6a).

To generate aerosol with high mass concentration, one should provide a high rate of evaporation of the maternal substance. As a result, the maternal substance is depleted after some time of the generator run, and the outlet aerosol concentration comes down. Therefore, it is important to know the period of time when the generator outlet concentration is stable. For this purpose, the temporal dependence of the outlet aerosol concentration is determined (Fig. 10) by sampling aerosol particles to filter 1 as shown schematically in Fig. 2. During this measurement, the methane flow rate was $F_{4}=0.13 \mathrm{~L} / \mathrm{min}$. As seen from Fig. 10, the aerosol concentration reaches the stationary value about $1 \mathrm{~min}$ after the start of running and then, after subsequent $3.5 \mathrm{~min}$, it comes down due to the depletion of maternal substance. Thus, there is a period of about $3.5 \mathrm{~min}$ when the aerosol concentration is approximately stable. During this period the aerosol-methane-air mixture 


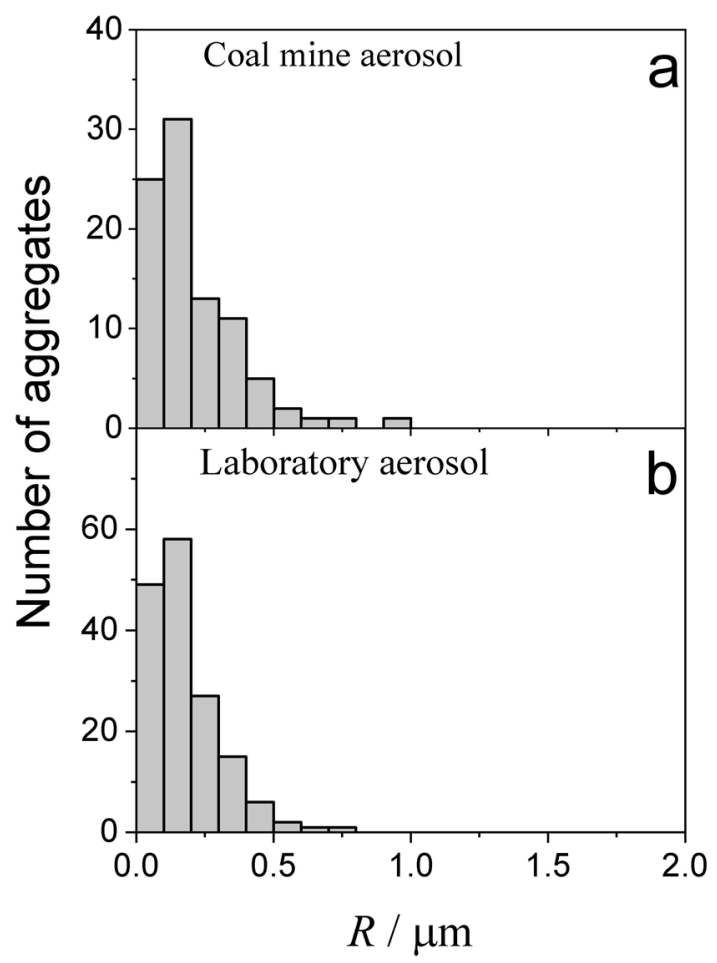

Fig. 6 Aggregate radius distribution: a coal mine aerosol, b laboratory aerosol $\left(T_{\mathrm{d}}=170 \mathrm{~K}\right)$

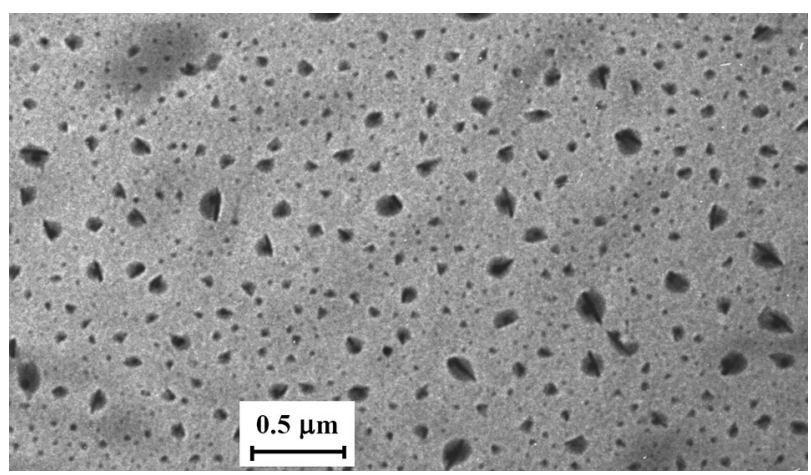

Fig. 7 Example of TEM image of aerosol particles generated in laboratory with the temperature of diluting gas equal to the room temperature

is blown through the bomb as described in Sect. 2.3. Then the valves $V_{2}$ and $V_{3}$ (Fig. 2) are closed, and the flow of reaction mixture is stopped.

The kinetics of an increase in the aerosol mass concentration in the bomb is measured by sampling the aerosol particles to filter 2 (Fig. 2) and weighting. Figure 11 shows an example of the dependence of aerosol mass concentration in the bomb on the time during which the reaction mixture is blown through the bomb. The aerosol mass concentration at the inlet is equal to that shown in Fig. 10. Initial time in Fig. 11 corresponds to $t_{1}$ in Fig. 10. Initially, the inlet aerosol concentration $C_{\text {inlet }}$ is constant, and the

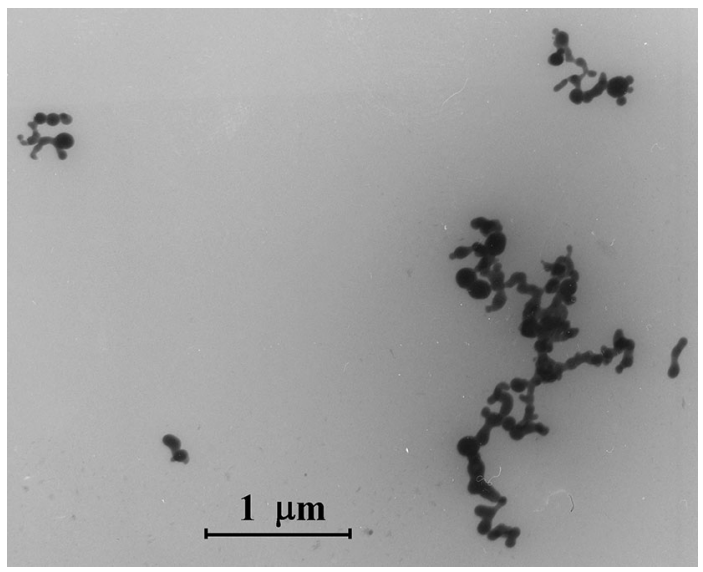

Fig. 8 Example of TEM image of laboratory aerosol particles at diluting gas temperature equal to $170 \mathrm{~K}$

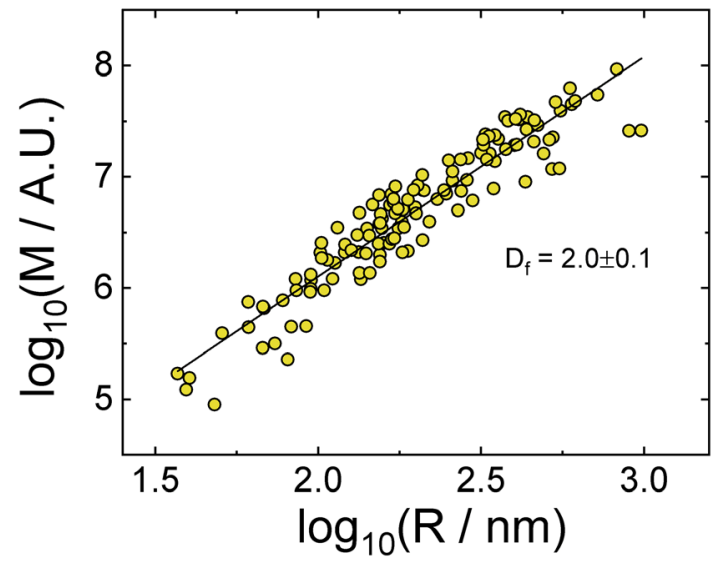

Fig. 9 Aggregate mass versus radius for the laboratory aerosol, determined from densitometric elaboration of TEM images. Solid line follows Eq. (1)

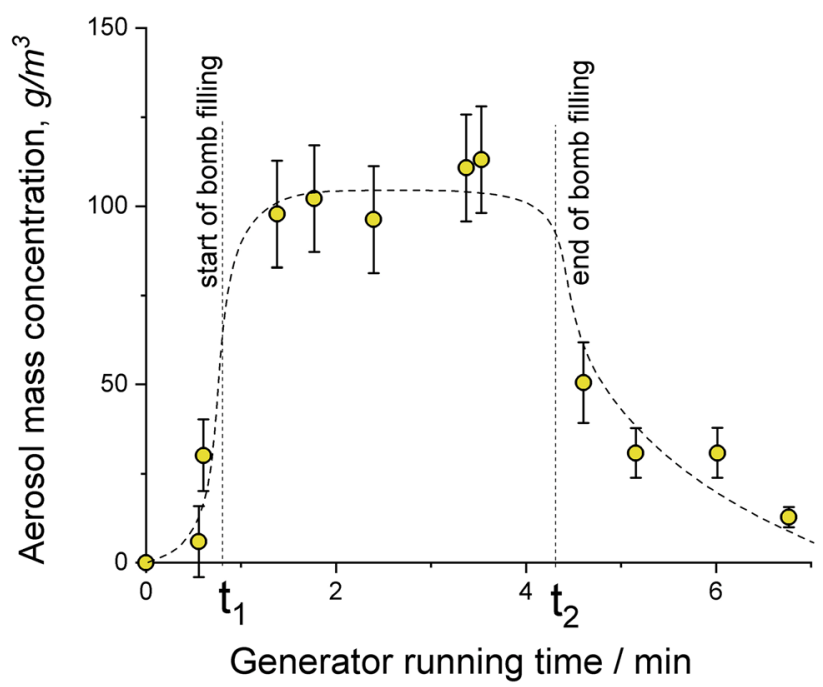

Fig. 10 Aerosol mass concentration at the bomb inlet as a function of the generator running time. Symbols-experimental measurements, dash line is an eye guide 


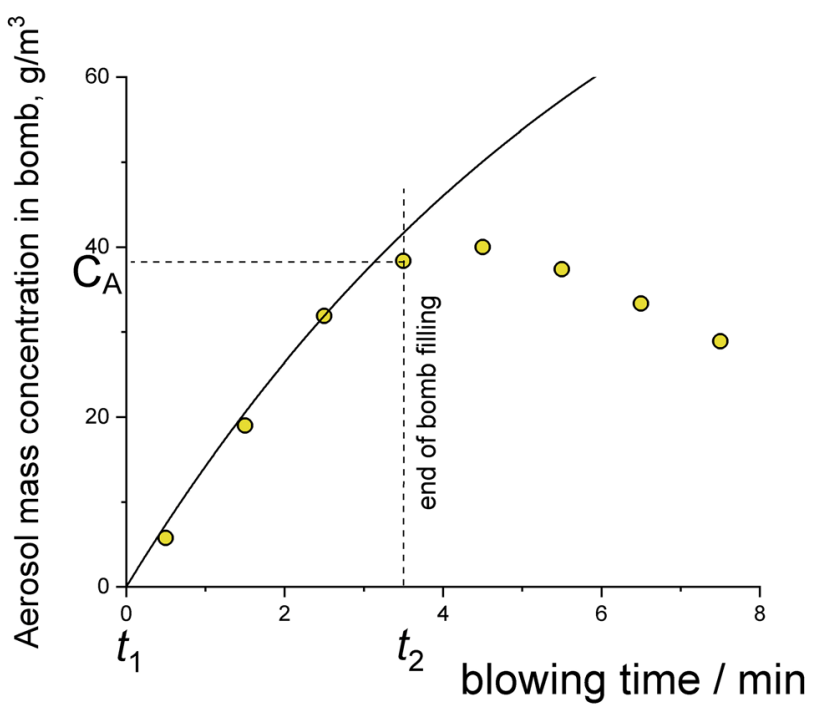

Fig. 11 Aerosol mass concentration in the bomb versus blowing time. Symbols-experimental values, solid line follows Eq. (3)

mass concentration $C$ inside the bomb is increasing with time according to the following equation for the reactor of ideal mixing

$C=C_{\text {inlet }}\left(1-e^{-t / \tau}\right)$.

where $\tau=V / F_{\text {inlet }}$ is the bomb characteristic time, $V$ is the volume of the bomb, $F_{\text {inlet }}=F_{1}+F_{2}+F_{3}+F_{4}$ is the inlet flow rate. One can see that at time $<t_{2}$, when the inlet concentration is constant, the inner aerosol concentration follows Eq. (3), but at longer times the experimentally measured concentration deviates from Eq. (3) because of the depletion of the maternal substance in the generator and, as a consequence, a decrease in the inlet aerosol concentration.

We refer to the aerosol mass concentration at the end of bomb filling as $C_{\mathrm{A}}$. This concentration is controlled by the initial mass of maternal substance. Figure 12 shows the dependence of the concentration $C_{\mathrm{A}}$ in the bomb on the mass of maternal substance in the saturation chamber. Figure 13a gives an example of pressure rise in the bomb after the ignition of reaction mixture with the aerosol mass concentration $C_{\mathrm{A}}=40 \pm 2 \mathrm{~g} / \mathrm{m}^{3}$ and methane molar concentration $3 \% \pm 0.2 \%\left(20 \mathrm{~g} / \mathrm{m}^{3}\right)$. It is convenient to characterize the explosivity of reaction mixture by the maximum rate of pressure rise $(\mathrm{d} P / \mathrm{d} t)_{\max }$ (Fig. 13b) as determined from the temporal pressure rise plots. Figure 14 shows the dependence of $(\mathrm{d} P / \mathrm{d} t)_{\max }$ on the aerosol mass concentration in the reaction mixture for methane concentration 3 molar\% as an example. One can see that the mixture is explosive at the aerosol concentration higher than $20 \mathrm{~g} / \mathrm{m}^{3}$.

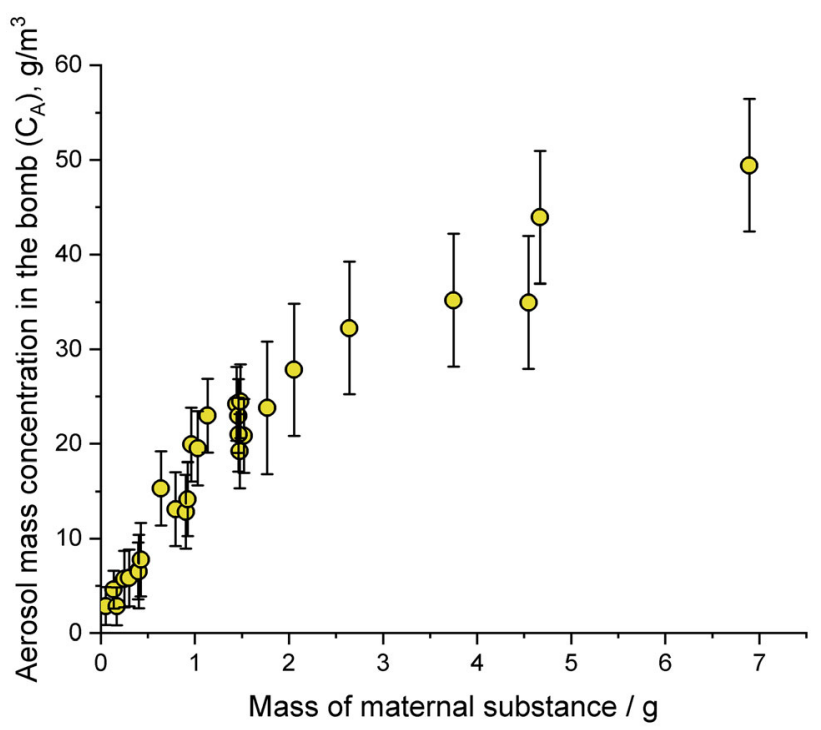

Fig. 12 Aerosol concentration in the bomb versus the mass of maternal substance charged to the aerosol generator

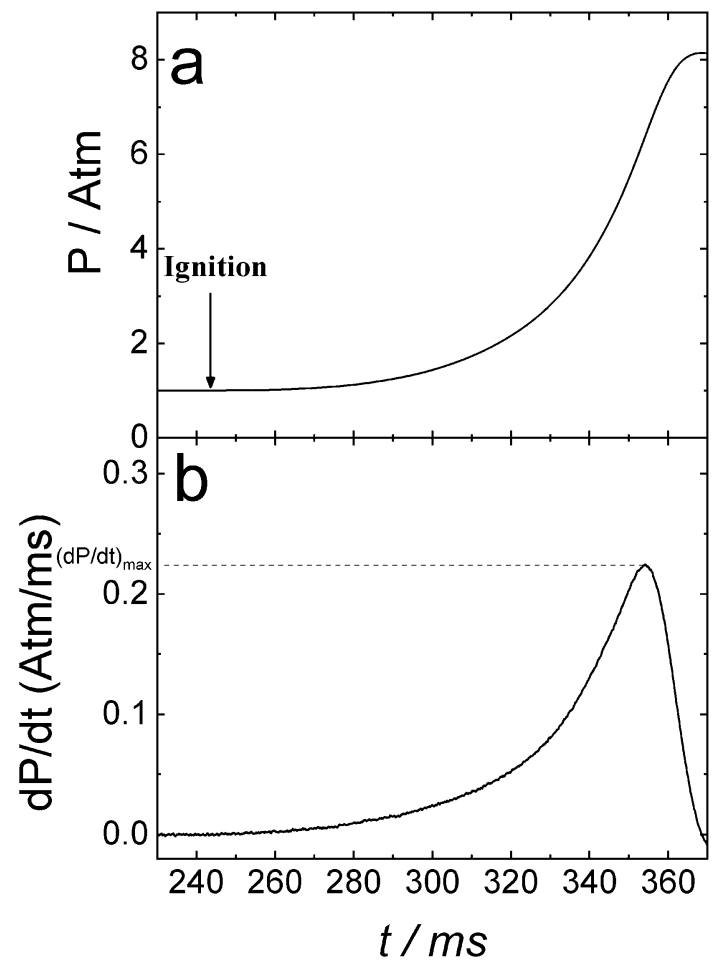

Fig. 13 Pressure (a) and time derivative (b) versus time for the combustion of aerosol/methane mixture in air. The aerosol and methane concentrations are 40 and $20 \mathrm{~g} / \mathrm{m}^{3}$, respectively

Figure 15 illustrates the explosivity of the mixtures of organic aerosol and methane in air. In some cases the lower explosive limit of the mixtures of different combustible gases with air can be characterized by the Le Chatelier additive principle (Mashuga and Crow 2000) 


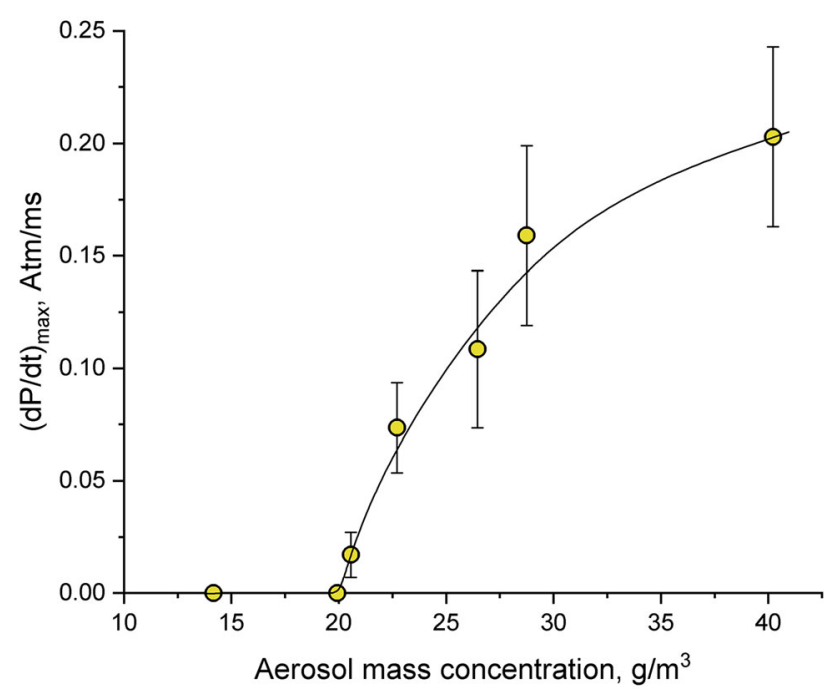

Fig. $14 \mathrm{~d} P / \mathrm{d} t_{\max }$ versus aerosol mass concentration in the reaction mixture. Methane concentration in the mixture is 3 molar\%. Solid line is an eye guide

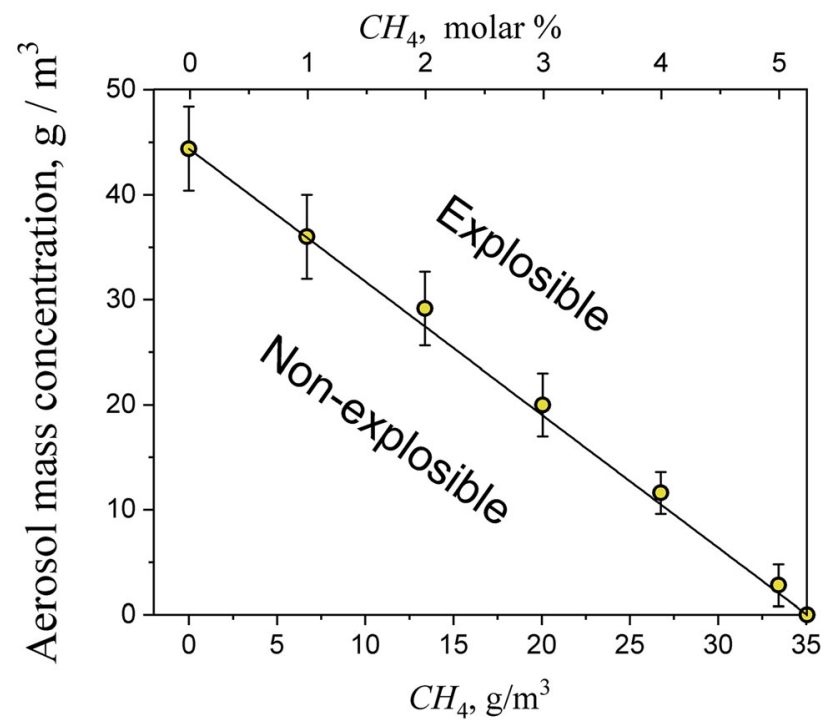

Fig. 15 Lower explosive limit for the mixture of aerosol and methane in air. Solid line follows Eq. (5)

$L F L_{\text {mix }}=\frac{1}{\sum_{i=1}^{N} \frac{y_{i}}{L F L_{i}}}$

where $y_{i}$ is the mole fraction of the $i$ th species (considering only the combustible components) in the mixture of minimum explosive concentrations, $L F L_{i}$ and $L F L_{\text {mix }}$ are the lower explosive limits of the $i$ th component and the mixture of flammable gases, respectively, $N$ is the number of flammable components. For the mixture of organic particles with methane in air, it is more convenient to represent the Le Chatelier additive principle as (Landman 1995)
$\frac{C_{\mathrm{p}}}{C_{\mathrm{p}}^{0}}+\frac{C_{\mathrm{CH}_{4}}}{C_{\mathrm{CH}_{4}}^{0}}=1$

where $C_{\mathrm{p}}$ is the minimum explosive concentration of aerosol particles in the mixture with methane concentration $C_{\mathrm{CH}_{4}} ; C_{\mathrm{p}}^{0}$ and $C_{\mathrm{CH}_{4}}^{0}$ are the minimum explosive concentrations of aerosol particles in air and methane in air, respectively. One can see from Fig. 14 that the explosivity of organic aerosol and methane in air is in good agreement with the Le Chatelier additive principle. The lower explosive limit for the pure organic aerosol in air is $44 \mathrm{~g} /$ $\mathrm{m}^{3}$.

\section{Conclusions}

An evaporation-nucleation approach is developed to synthesize the organic aerosol similar to that formed in coal mines during the operation of a longwall shearer. The lower explosive limit of the mixture of organic aerosol with methane in air is studied in a spherical bomb. The mixture is ignited with a $\mathrm{Ni} / \mathrm{Cr}$ heater. Pressure rise is recorded with an inductive pressure transducer. The concentrations of aerosol and methane are varied in the ranges of $0-50 \mathrm{~g} / \mathrm{m}^{3}$ and 0-6.5 molar\%, respectively. It is shown that the lower explosive limit is in accordance with the Le Chatelier additive principle. Using the experimentally measured flammability limit diagram, the upper aerosol and methane concentrations providing an acceptable safety factor can be determined.

Acknowledgements The reported study was funded by RFBR and Novosibirsk region (Grant No. 19-43-540009).

Open Access This article is licensed under a Creative Commons Attribution 4.0 International License, which permits use, sharing, adaptation, distribution and reproduction in any medium or format, as long as you give appropriate credit to the original author(s) and the source, provide a link to the Creative Commons licence, and indicate if changes were made. The images or other third party material in this article are included in the article's Creative Commons licence, unless indicated otherwise in a credit line to the material. If material is not included in the article's Creative Commons licence and your intended use is not permitted by statutory regulation or exceeds the permitted use, you will need to obtain permission directly from the copyright holder. To view a copy of this licence, visit http://creativecommons. org/licenses/by/4.0/.

\section{References}

Ajrash MJ, Zanganeh J, Moghtaderi B (2016) Methane-coal dust hybrid fuel explosion properties in a large scalecylindrical explosion chamber. J Loss Prev Process Ind 40:317-328

Ajrash MJ, Zanganeh J, Moghtaderi B (2017) The effects of coal dust concentrations and particle sizes on the minimum auto-ignition temperature of a coal dust cloud. Fire Mater 41(7):908-915 
Baklanov AM, Valiulin SV, Dubtsov SN, Zamashchikov VV, Klishin VI, Kontorovich AE, Korzhavin AA, Onishchuk AA, Paleev DYu, Purtov PA (2015) Nanoaerosol fraction of man_made coal dust and its effect on the explosion hazard of dust-methane-air mixtures. Dokl Phys Chem 461(Part 1):57-60

Cashdollar KL (2008) Frictional ignition of methane-air in the presence of liquid hydrocarbons, technology news (National Institute for Occupational Safety and Health), no. 530, pp 1-2; DHHS publication; no. (NIOSH) 2008-124

Cheng J (2018) Explosions in underground coal mines. Risk Assessment and Control. Springer, Cham

Cheng L, Furno AL, Courtney WG (1987) Reduction in frictional ignition due to conical coal-cutting bits, Report of Investigations 9134, Bureau of Mines, United States Department of the Interior

Eckhoff RK (2012) Does the dust explosion risk increase when moving from $1 \mathrm{~m}$-particle powders to powders of nm-particles? J Loss Prev Process Ind 25(3):448-459

Friedlander SK (2000) Smoke, Dust, and Haze. Oxford University Press, New York/Oxford

Jang HD, Friedlander SK (1998) Restructuring of chain aggregates of Titania nanoparticles in the gas phase. Aerosol Sci Technol 29:81-91

Katzer M, Weber AP, Kasper G (2001) Collision kinetics and electrostatic dispersion of airborne submicrometer fractal agglomerates. J Colloid Interface Sci 240:67-77

Kissell FN, Cecala AB (2006) Preventing methane ignitions at longwall faces. In: Kissell FN (ed) Handbook for methane control in mining (information circular 9486), chapter 4, pp 5562

Krog RB, Schatzel SJ (2009) Frictional ignitions in underground bituminous coal operations 1983 to 2005. Min Eng 61(8):28-35

Landman GVR (1995) Ignition behaviour of hybrid mixtures of coal dust, methane, and air. J South Afr Inst Min Metall 95(1):45-50

Mashuga CV, Crow DA (2000) Derivation of Le Chatelier's mixing rule for flammable limits. Process Saf Progress 19(2):112-117

Onischuk AA, Vosel SV, Borovkova OV, Baklanov AM, Karasev VV, di Stasio S (2012) Experimental study of homogeneous nucleation from the bismuth supersaturated vapor: evaluation of the surface tension of critical nucleus. J Chem Phys 136:224506$1-224506-18$

Onischuk AA, Tolstikova TG, Baklanov AM, Khvostov MV, Sorokina IV, Zhukova NA, An'kov SV, Borovkova OV, Dultseva GG, Boldyrev VV, Fomin VM, Huang GS (2014)
Generation, inhalation delivery and anti-hypertensive effect of nisoldipine nanoaerosol. J Aerosol Sci 78:41-54

Onischuk A, Dubtsov S, Baklanov A, Valiulin S, Koshlyakov P, Paleev D, Mitrochenko V, Zamashchikov V, Korzhavin A (2017) Organic nanoaerosol in coal mines: formation mechanism and explosibility. Aerosol Air Qual Res 17(7):1735-1745

Pejic LM, Torrent JG, Añez NF, Escobar JMM (2017) Prevention and protection against propagation of explosions in underground coal mines. J Min Inst 225:307-312

Phillips HR (1996) Identify methods to reduce the risk of explosions and fires caused by frictional ignition hazards. Final Project Report, No. COL226, University of the Witwatersrand, Johannesburg

Pomroy WH, Carlgiet AM (1995) Analysis of underground coal mine fire incidents in the United States from 1978 through 1992, Information Circular 9426, United States Bureau of Mines

Rogak SN, Baltensperger U, Flagan RC (1991) Measurement of mass transfer to agglomerate aerosols. Aerosol Sci Technol 14:447-458

Samson RJ, Mulholland GW, Gentry JW (1987) Structural analysis of soot agglomerates. Langmuir 3:272-281

Sapko MJ, Cashdollar KL, Green GM (2007) Coal dust particle size survey of US mines. J Loss Prev Process Ind 20(4-6):616-620

Tan B, Liu H, Xu B, Wang T (2020) Comparative study of the explosion pressure characteristics of micro- and nano-sized coal dust and methane-coal dust mixtures in a pipe. Int $\mathrm{J}$ Coal Sci Technol. https://doi.org/10.1007/s40789-019-00289-w

Trueman R (1985) A literature review of the ignition of methane-air mixtures by coal-cutting picks. J S Afr Inst Min Metall 85(7):209-215

Valiulin SV, Baklanov AM, Dubtsov SN, Zamashchikov VV, Klishin VI, Kontorovich AE, Korzhavin AA, Onishchuk AA, Paleev DYu, Purtov PA, Kuibida LV (2016) Influence of the nanoaerosol fraction of industrial coal dust on the combustion of methane-air mixtures. Combust Explos Shock Waves 52:405-417

Wang G, Ren T, Cook CD (2014) Goaf frictional ignition and its control measures in underground coal mines. In: He X, Mitri H, Nie B, Wang Y, Ren TX, Chen W, Li X (eds) Progress in mine safety science and engineering II: proceedings of the 2 nd international symposium of mine safety science and engineering. Taylor \& Francis Group, United Kingdom, pp 451-459 